\title{
Sphenophyllum paranaensis n. sp. DA FORMAÇĀO RIO DO RASTO (PERMIANO SUPERIOR) DE DORIZON, ESTADO DO PARANA
}

\author{
OSCAR RÖSLER \\ ROSEMARIE ROHN ${ }^{2}$
}

\begin{abstract}
This paper describes a new species of Sphenophyllum (S, paranaensis n. sp.) from the Rio do Rasto Formation, Serrinha Facies, cropping out along the Dorizon-Paulo Frontin road (State of Pa. rana, Brazil), $1.5 \mathrm{~km}$ south of the main church of Dorizon. The new species is based on isolated leaves, verticils and articulated stems. A few lascinated leaves which occur dispersed at the same outcrop may be interpreted as a polymorphic variation of the new species, but until further data become available they are here called Sphenavhyllum cf. S, thonii. In fact, both forms of this genus from Dorizon are similar to specimens assigned to $S$, thonii in Africa but smaller than type material of this species.
\end{abstract}

\section{INTRODUÇÃo}

O afloramento de Dorizon (RÖSLER, 1978b) se caracteriza paleontologicamente pela abundância extraordinária de impressరes folia. res relacionadas a dois géneros: Glossopteris e Sphenophyllum, além de Paracalamites e conchostráceos.

As treze espécies do género Glossopteris foram descritas por ROHN et al. (1984) e os conchostráceos (Monoleaia unicostata) foram descritos por ROHN \& RÖSLER (no prelo). O presente trabalho visa descrever as formas relacionadas a Sphenophyllum deste afloramento, antes referidas na literatura como Sphenophyllum $\mathrm{cf}$. S. speciosum (RÖSLER, op. cit.).

\section{DESCRIÇÃO E DISCUSSÃO}

Sphenophylhum KOENIG, 1825, Icones fossilium sectiles : $4 \mathrm{p} ., 19 \mathrm{pls}$, Londres.

Sphenophyllum paranaensis sp. nov. Est. 1, figs. 1-4, 7-9; Est. 2, figs. 1-5; Est. 3, figs. 1-3.

Sinonimia: Sphenophyllum of. S. speciosum, RÖSLER, 1978a: 88; RÖSLER, 1978b : 128 , Est. 1, fig. 7.

Holótipo: GP/3T-1481, Est. 3, fig. 2.

Material estudado: (Série típica: folíolos isolados verticilos em conexão com caules articulados) : Holótipo: GP/3T-1481; Parátipos:
GP/3T-560, 1474a/b, 1475, 1476, 1477, 1478 $\mathrm{a} / \mathrm{b}, 1480 \mathrm{bP}, 1482,1483,1484,1485,1486$, $1487,1488,1489 \mathrm{~b}, 1490,1491 \mathrm{~A}, \mathrm{~B}, 1492 \mathrm{aB}$, $1493 \mathrm{~B}, 1494,1495 \mathrm{a}, 1496 \mathrm{a} / \mathrm{b}, 1497 \mathrm{aF}, 1498$, $1499,1500,1501 \mathrm{G}, 1502 \mathrm{a}, 1503,1504,1505$, 1506,1508 . Caules articulados sem folíolos, porém idénticos aos desta espécie:GP/3T-1497a, $1508 \mathrm{~A}$.

Local tipico: Afloramento ao lado direito da rodovia Dorizon - Paulo Frontin (PR) a 1,5 $\mathrm{km}$ da igreja de Dorizon; Sigla AF/GP 79 RR/PR (RÖSLER, 1978b).

Estrato típico: Formação Rio do Rasto

Derivaçđo do nome: Alusĩo ao Estado do Paraná onde se situa o local típico.

Diagnose: Verticilos com 6 folíolos de igual tamanho. Predominam folíolos obovóides, com maior largura atingida próximo à base do terço distal, em média de $0,9 \mathrm{~cm}$ e comprimento, em média de $1,8 \mathrm{~cm}$, raramente atingindo mais que $2,3 \mathrm{~cm}$. Base do folíolo com um feixe vascular do qual partem 4 nervuras, as quais se dicotomisam até 5 vezes. Nervuras laterais sempre curvas, sendo que as primeiras a atingirem a margem o fazem muito próximo a base do folíolo. Nervaçāo densa: cerca de 65 nervuras atingem a margem dos folíolos maiores (entre 2 a 3 por $\mathrm{mm}$ ).

Descrigēo: Folíolos ocorrem quase sem. pre destacados e rompidos próximo a base. Apenas seis casos de folfolos em posiçato verticilar foram encontrados, dentre os quais 2 es-

Instituto de Geociencias, USP

' Pós-Graduanda do Instituto de Geociências, USP e Bolsista da FAPESP. 
pécimes apresentam verticilos completos, formados por 6 folfolos semelhantes entre si quanto ao tamanho e forma, embora tenham peque. nas variaçбos de contorno. As impressóes de caules apresentam estrias longitudinais pouco distintas geralmente em número de 4 . Os entrenós são longos e estreitos, com relações largura/ comprimento próximas a $1 / 6$, aumentando em direção ao nó até 1/3. Caules desse tipo (Est. 3, fig. 4), porém desprovidos de folíolos, ocorrem também em certo número, porém em estratos distintos daqueles nos quais os folíolos destacados sáo abundantes. Esta situação sugere que os caules desprovidos de folfolos representam elementos do mesmo tipo de planta, que teriam sofrido maior transporte.

Os folíolos apresentam variaçøes de forma e de tamanho no âmbito das diferenças representadas na Fig. 1, variando a forma de obovóide a levemente espatulada. A margem é lisa, sendo a margem distal inteira, simplesmente convexa (Est. 1, fig. 2) ou levemente lobada (Est. 1, fig. 3). Neste segundo caso, há quase sempre alguma assimetria do folíolo, conferida pela posiçáo e profundidade das duas concavidades interlobares. As margens laterais sao geralmente convexas, tendendo as vezes a retili. neas. A maior largura do folíolo é atingida em torno da porçđo proximal do seu terço distal.

Somente as nervuras da porção mediana do folíolo são mais ou menos retilíneas. As de. mais apresentam sempre alguma curvatura. A parte mais proximal da base dos folíolos não é claramente visível quando reunidos em vertici. los, e está ausente na quase totalidade dos folío. los destacados. Em apenas um caso (Est, 1, fig. 9; Est. 2, fig. 5) vé-se um robusto feixe vascular penetrando na base, do qual partem 4 ramos, talvez representando 2 níveis de dicotomias muito próximas entre si. Cada um desses 4 ramos sofre de 1 a 5 dicotomias, de forma que nos folíolos grandes, cerca de 65 nervuras atingem a margem (2 a 3 por $\mathrm{mm}$ ), formando assim uma nervação relativamente densa. As primeiras nervuras, mais laterais, atingem a margem a poucos milímetros além da base, condicionando assim um bordo distal extremamente amplo. Embora o numero de nervuras que atingem a margem seja aparentemente menor nos folfolos de pequeno tamanho, o padrao de nervaçđo mantém-se consideravelmente constante entre foliolos de diferentes tamanhos (Comparar figs. 1 e 3 da Est. 1 e figs. 14 da Est. 2).

Não ocorrem casos de compressøes carbonificadas, e portanto, não é aplicável o método de transferência. Na realidade não há mais nenhum resíduo cuticular. Contudo, as impres- sốes são de tão boa qualidade que em alguns casos podem ser observados, em relevo, os contornos das células epidérmicas (Est. 1, figs. 7 e $8 \mathrm{e}$ Figs. 2 e 3 do texto).

Nas áreas intervasculares da porção média do foliolo, aparecem células de contorno ondulado, alongadas na direçá longitudinal do folíolo e irregularmente intercaladas por células menores e mais isodiamétricas. As áreas vasculares apresentam estrias longitudinais, delimitando na porção média do folíolo, 4 faixas paralelas e de mesma largura, nas quais não foram observadas divisōes transversais. Algumas impressōes apresentam as áreas vasculares muito deprimidas formando sulcos bem marcados. Outras, nas quais as áreas vasculares não formam sulcos, apresentam, além disso, as células das áreas intervasculares com menor comprimento. Estas diferenças, observadas numa mesma porção dos folíolos poderiam corresponder as faces abaxiais e adaxia is respectivamente.

O comprimento dos folíolos é em média de $1,8 \mathrm{~cm}$, variando entre 1 e $2,8 \mathrm{~cm}$ (embora apenas um exemplar exceda $2,3 \mathrm{~cm}$ ). A largura é em média de $0,9 \mathrm{~cm}$, variando entre $0,4 \mathrm{e}$ $1,4 \mathrm{~cm}$.

A relaçđo comprimento/largura varia entre 1,4 e 2,0 mantendo-se predominantemente em torno de 1,6 (folíolos menores) e 1,8 (folíolos maiores). E necessário lembrar que os foIfolos destacados estão rompidos muito próximo a base. As medidas aqui consideradas referem-se aos exemplares mais completos. Contudo, presume-se que o cumprimento original dos folíolos tenha sido cerca de $5 \%$ maior que os valores aqui mencionados.

Discussão: Num estudo preliminar de fósseis dessa mesma localidade (RÖSLER, 1978b). foi verificada a presença do género Sphenophyllum, porém constatou-se que os folfolos apresentavam algumas diferenças em relaçao as espécies já descritas, com certa semelhança com $S$. speciosum e $S$, thonii var. minor, pelo que foram cautelosamente denominadas de Sphenophyllum $\mathrm{cf}$. S speciosum. Através do presente estudo, contando também com exemplares coletados mais recentemente, póde-se demonstrar que o verticilo não apresenta a forma Trizygia como em $S$. speciosum.

Além disso S. paranaensis sp. nov. apresen. ta maior densidade de nervaça, maior curvatura das nervuras e foliolo com menor relação comprimento/largura, afastando-se definitivamente daquela espécie.

$S$. paranaensis sp. nov. apresenta maior semelhança com $S$, thonii var. minor STERZEL 1895 e talvez nđo seja coincidência, por sua vez, a semelhança entre Sphenophyllum sp. (descrita 


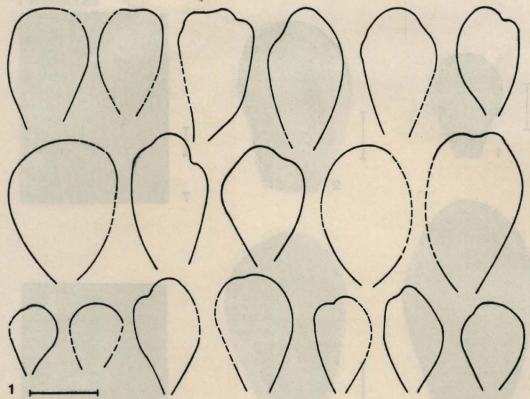

Fig. 1 - Esquema representativo da variabilidade de Sphenophyllum paraneensis n. sp. quanto a forma e dimensões; escala $=10 \mathrm{~mm}$.

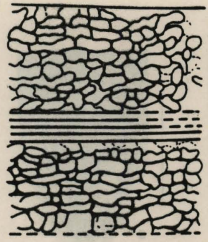

2

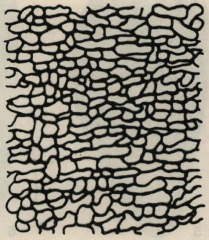

3

Figs. 2, 3 - Representaçđo das impresšies de contornos cetulares na superfície foliar de Sphenophyllum paranaensis n. sp. $(2$; possivelmente superfície inferior, GP/3T-1485; 3 : possivelmente superffcie superior, GP/3T-1474a/b); escala $=0,25 \mathrm{~mm}$. 
RÖSLER, O. \& ROHN, R.
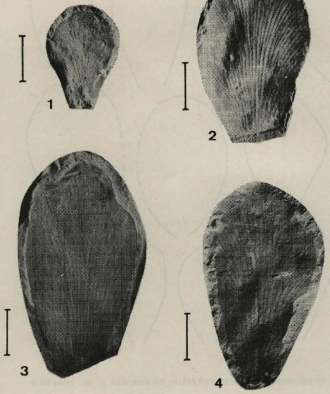

8

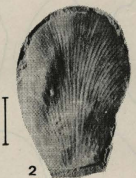

\section{7}
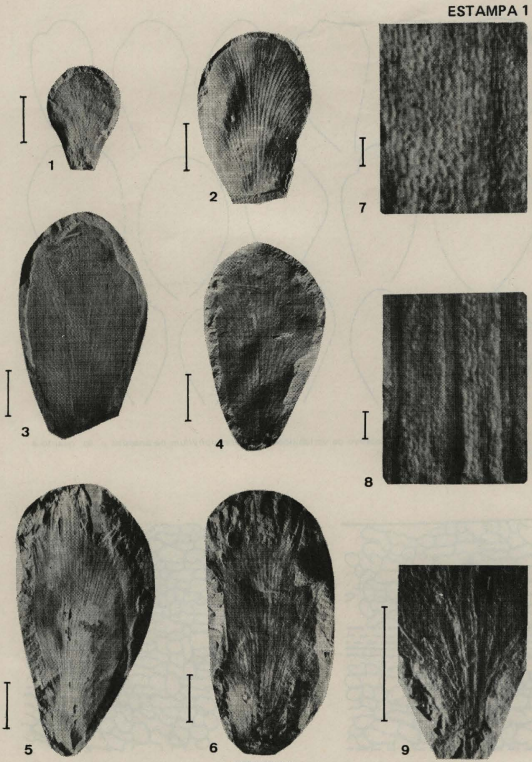

ESTAMPA I

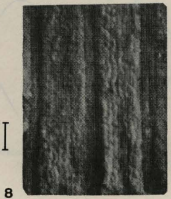

Figs, 1 a 4 - Sphenophyllum paranaensis n. sp. $11:$ GP/3T-1482, $2:$ GP/3T-560, $3:$ GP/3T-1477 e $4:$ GP/3T. 1492aB); escala = $5 \mathrm{~mm}$. Figs. 5, 6 - Sphenophyllum cf. S. thonii Mahr (5: GP/3T-1506B, 6: GP/3T-1408aR); escala $=5 \mathrm{~mm}$. Figs, 7, 8 - Impressठ̈es de contornos celulares na superfície foliar de Sphenophyllum paranaensis $\mathrm{n}$, sp. ( 7 ; possivelmente superfície superior, GP/3T-1474a/b; 8 : possivelmente superffcie inferior, GP/3T-1485); escala = $0,25 \mathrm{~mm}$. Fig. 9 - Detalhes de porçto basal de Sphenophyllum paranaensis $\mathrm{n}$, sp. (GP/3T-1489b); escala $5 \mathrm{~mm}$. 
adiante e que ocorre nos mesmos níveis de $S$. paranaensis $\mathrm{sp}$. nov.) com $S$. thonii MAHR 1868. Entretanto, $S$. paranaensis sp. nov. revela um tipo de poliformismo foliolar ao longo da planta que aparentemente se distingue um pouco dessa variedade. Seriam pequenas diferenças

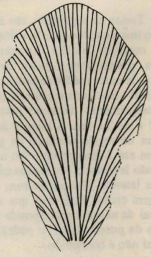

1

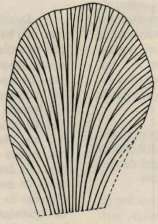

2

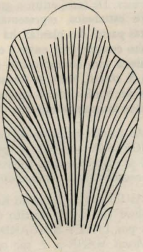

3
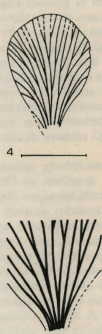

5

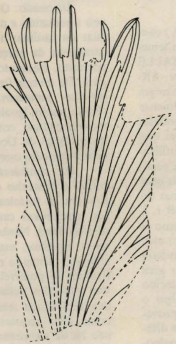

6

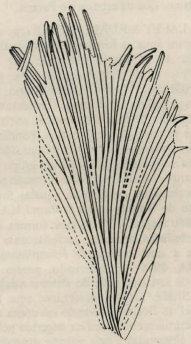

7

ESTAMPA 2

Figs. 1 a 4 - Representaçăo de Sphenophyllum poranaensis n. sp. (1 : GP/3T-1492aB; 2 : GP/3T-560; $3:$ GP/ $3 \mathrm{~T}-1477$ e 4 : GP/3T-1482); escaia $=5 \mathrm{~mm}$. Fig. 5 - Representaçđó da porçఫo basal de Sphenophyllum paranaensis (GP/3T-1489b); escala $=5 \mathrm{~mm}$. Figs, 6, 7 - Representaçio de Sphenophyllum cf. S. thonii Mahr (6 : GP/3T-1480aR; $7: \mathrm{GP} / 3 \mathrm{~T}-1506 \mathrm{~B}$ ); escala $=5 \mathrm{~mm}$. 
ao nível morfologico, que isoladamente poderiam ter pouco significado taxonòmico. Porém, tomam sentido quanso se analisa o aspecto do tamanho médio dos folíolos que é claramente inferior em $S$. paranaensis sp. nov. que $S$. thonii var. minor. De fato, entre o grande número de foliolos estudados, representando certamente distintas partes das plantas, há uma variaçđo de tamanho considerável, entre 1 e $2,3 \mathrm{~cm}$. A grande maioria tem comprimento inferior a $2 \mathrm{~cm}$. Já em $S$. thonii, tanto as formas lascinadas como as de bordo inteiro apresentam média de tamanhos incomparavelmente maior.

As formas patagônicas descritas por ARCHANGELSKY (1960) e por ARRONDO (1972) são também mais robustas, além de me. nos obovóides que $S$, paranaensis sp. nov.

As formas da Bacia do Karroo no Sul da Zimbabwe (Rodésia), distrito de Wankie, atriburdas por LACEY \& HUARD-MOINE (1966) a $S$. thonii MAHR s. 1 . são semelhantes a $S$. paranaensis sp. nov., tendo também os comprimentos dos folíolos um pouco maís próximos dos desta espécie novia. Pela ilustraçáo de LA. CEY \& HUARD-MOINE (op, cit., pl, 1, fig. 1) percebe-se porém, que a forma dos folíolos é mais espatulada e a relação comprimento/largura é menor que na espécie do Paraná.

LACEY \& HUARD-MOINE ( $o p$, cit.) consideraram aquelas formas africanas muito semelhantes as da China, descritas por HALLE (1927) e às da Patagônia, descritas por ARCHANGELSKY $(1958,1960)$. Porém, chamam a atençđo para o tamanho consideravelmente menor, além de outras diferenças, entre aquelas formas africanas e as européias. Ponderam que o nome Sphenophyllum thonii tem sido utilizado para designar membros de um grupo de espécies muito semelhantes entre si, razão pela qual provisoriamente designaram aquelas formas do Distrito de Wankie como S. thonii MAHR s. I. ("sentido amplo"). Tanto essas formas, como as aqui estudadas, poderiam perfeitamente ser atriburdas a uma espécie de Parasphenophyllum ASAMA, 1970. Considerando, porém, o grau maior de artificialidade do sistema estabelecido por ASAMA (1970), preferiu-se aqui julgar o material de Dorizon, levando em conta a provável discriminação específica sugerida pelas diferenças observadas e pela própria situação paleofitogeográfica, como espécie nova.

Sphenophyllum cf.S. thonii MAHR

\section{Material estudado: GP/3T-1480aR, 1506B e 1507 .}

Procedencia: Dorizon, PR., Fm. Rio do Rasto: AF/GP-79 RR/PR (RÖSLER, 1978b).

Descriçăo: Todos os espécimes são isolados, não havendo informaçøes quanto a disposição verticilar ou conexão caulinar. Apresentam forma espatulada, porém com a maior largura atingida em torno da parte média da porção distal. A margem distal é lascipada e a lateral tende a retilínea. $\mathrm{O}$ comprimento, faltando parte da porção proximal é de $2,6 \mathrm{~cm}$. A largura atinge $1,2 \mathrm{~cm}$. Nervuras da região mediana da parte conservada sofrem até 3 dicotomias e são retilí. neas. As demais são levemente arqueadas em direção às margens laterais. Nas partes bem conservadas da margem distal, observa-se que a cada subdivisáo final da nervura corresponde uma lasćnea. $\mathrm{Na}$ falta da porçđo basal, o padrão da nervação proximal nå é conhecido.

Alguns contornos celulares estão impres. sos sem grande nitidez na superfície do folíolo, ao longo da qual aparentemente mantêm certa uniformidade. São células alongadas no sentido do eixo do folíolo e tếm contornos suave. mente ondulados.

Discussāo: O número de folíolos disponiveis é reduzido e não há casos de conexão verticilar ou caulinar nem casos de preservação dos caracteres da porção basal do folíolo. Não há, portanto, elementos para uma identificaçato segura. Da mesma forma que ocorre com Sphenophyllum paranaensis, há semelhança com $S$. thonii, porém igualmente ocorrem diferenças da mesma ordem, como o tamanho bem menor do material de Dorizon. O número de dicotomias é também menor.

Há considerável coincidência quanto a forma e tamanho com $S$. spinosum da China. Embora os folíolos aqui tratados sejam dispersos, numerosos caules articulados ocorrem no mesmo nivel. Nenhum destes, entretanto, apresenta espinhos, característicos daquela espécie chinesa, tornando menos provável tal coespecificidade. É possível que esses folíolos representam variaçбes polimórficas que teriam existido nos individuos relacionados a $S$. paranaensis, como alias acontece $\operatorname{com} S$. thonii. Contudo, ño ha de momento, condiçбes para confirmar tal hipotese. Por este motivo, preferiu-se denominar preliminarmente estas formas de Sphenophyllum $\mathrm{cf}$. S, thonii. 
Paleobotânica e Palinologia na Am. do Sul - 1983 - Bol, IG-USP, Inst, de Geociencias, USP, 15:13-150, 1984

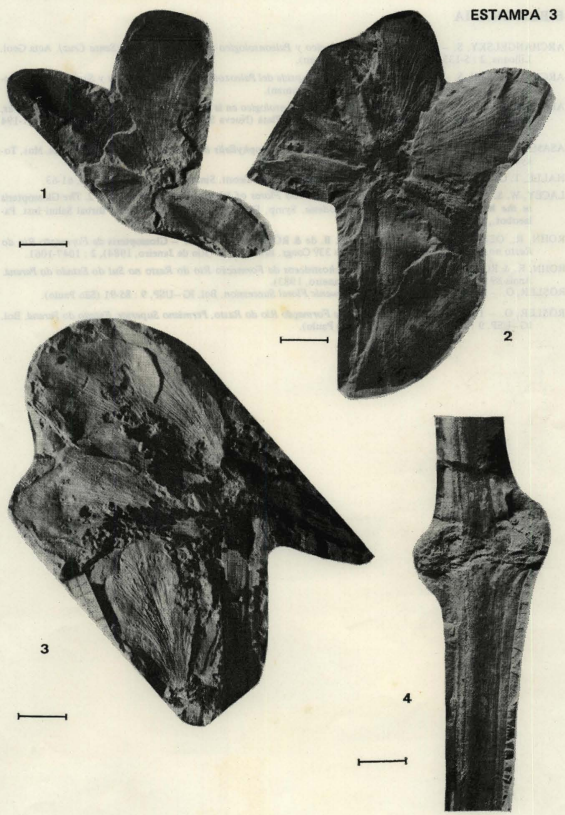

ESTAMPA 3

Figs, 1 a 3 -Verticilos foliares de Sphenophyllum paranaensis n. sp. 11 ; GP/3T-1497aF; 2 : holotipo, GP/3T. 1481 - 3: GP/3T-1501G); Escala $=5 \mathrm{~mm}$. Fig. 4 - Caule, provaveimente de Sphenophyllum paranaensis $n$. sp. (GP/ $3 T-1479 a)$; escala $=5 \mathrm{~mm}$. 


\section{BIBLIOGRAFIA}

ARCHANGELSKY, S. - 1958 - Estudio Geologico y Paleontologico del Bajo de Leona (Santa Cruz). Acta Geol. Lilloana, $2: 5-133$, fig. 1-56, 1 map. (Tucuman).

ARCHANGELSKY, S, - 1960 - Lycopsida y Sphenopsida del Paleozoico superior de Chubut y Santa Cruz, Patagonia. Acta Geol. Lilloana, $3: 21-36,11$ lam, (Tucuman).

ARRONDO, O. G. - 1972 - Estudio Geologico y Paleontologico en la Zona de la Estancia La Juanita y Alredores, Provincia de Santa Cruz, Argentina, Rev, Mus. La Plata (Nueva Ser.), Sec. Paleont., 7 (Paleont. 43) : 1.194 (La Plata).

ASAMA, K. - 1970 - Evolution and Classification of Sphenophyllalis in Cathaysia Land. Bull. Nat. Sci. Mus. Tokyo, 13(2):291-317, 7 pl. 1 tb., 3 figs. (Tokyo).

HALLE, T. G. - 1927 - Paleozoic Plants from Central Shansi, Paleont. Sinica, A, 2(1): 236-239, pl. $61-63$.

LACEY, W. S. \& HUARD-MOINE, D. - 1966 - Karroo Floras of Rhodesia and Malawi, Part. 2. The Glossopteris in the Wankie District of Southern Rhodesia. Symp. Flor. Stratigr. Gondwanaland, Birbal Sahni Inst. Palaeobot, , p. 13-25(Lucknow).

ROHN, R., OLIVEIRA-BABINSKI, M. E. C. B. de \& RÖSLER, O. - 1984 - Glossopteris da Formaça Rio do Rasto no Sul do Estado do Parand. Anais 330 Congr. Brasil, Geol, (Rio de Janeiro, 1984), 2 : $1047-1061$.

ROHN, R. \& ROSLER, O. - no prelo - Conchostriceos da Formaçäo Rio do Rasto no Sut do Estado do Parand. Anais 80 Congr. Bras. Paleont, (Rio de Janeiro, 1983).

ROSLER, O. - 1978a - The Brazillian Eogondwanic Floral Succession. Bol, IG-USP, $9: 85-91$ (Sāo Paulo).

RÓSLER, O. - $1978 \mathrm{~b}$ - Novas Ocorréncias na Formaçao Rio do Rasto, Permiano Superior, Estado do Parand, Bol. IG-USP, 9 ; 127-132, 3 figs., 1 est. (Sฮ̃o Paulo). 